\title{
KESETARAAN GENDER PADA ABAD XIX DI INDONESIA DALAM KARYA RA KARTINI
}

\section{GENDER EQUALITY IN THE XIX CENTURY IN INDONESIA IN THE WORKS OF RA KARTINI}

\author{
Ari Hermawan ${ }^{1}$, Budi Purnomo ${ }^{1}$, Anny Wahyuni ${ }^{1}$ \\ ${ }^{1}$ Pendidikan Sejarah, Universitas Jambi, Indonesia \\ ${ }^{1}$ Email: arihermawanbangko@gmail.com
}

\begin{abstract}
Abstrak : Munculnnya gender di Indonesia pada abad XIX di tandai dengan pergerakan para kaum perempuan. Dalam artikel ini penulis telah melakukan penelitian dengan judul yang diangkat adalah "Kesetaraan Gender Pada Abad XIX Di Indonesia Dalam Karya RA Kartini. Penelitian inipun bertujuan guna untuk mendeskripsikan dan mendapatkan gambaran secara rinci berkenaan dengan kesetaraan gender yang digaungkan oleh RA Kartini. Dalam artikel ini penulis mengunakan metode penelitian sejarah dengan pendekatan studi pustaka. Pergerakan kaum perempuan pada abad XIX sangat terbatas sekali dikarenakan pemikiran masyarakat kala itu yang mempertahankan adat istiadat nenek moyang secara turun termurun sehingga dikenallah istilah "the second sex" anggapan itu melekat baik dari pribumi maupun pihak penjajah. Para kaum perempuan merasakan tidak adilnya budaya masyakarat kala itu. Maka dari itu, muncullah pemberontakan oleh kaum perempuan untuk mengahncurkan persepsi yang menyebabkan ketidakadilan itu. Sehingga muncullah RA Kartini sang penggaung kesetaraan gender dan sebagai pelopor emansipasi wanita dalam pendidikan di Indonesia pada abad XIX.
\end{abstract}

Kata kunci: Karya,Gender, Teladan, Perjuangan RA Kartini

\begin{abstract}
The emergence of gender in Indonesia in the XIX century was marked by the movement of women. In this article the author has conducted research with the title raised is "Gender Equality in the XIX Century in Indonesia in the Work of RA Kartini. This study also aims to describe and get a detailed description of the gender equality echoed by RA Kartini. In this article, the author uses the historical research method with a literature study approach. The movement of women in the XIX century was very limited because of the thinking of the people at that time who maintained the customs of their ancestors from hereditary, so that the term "the second sex" was recognized. This assumption was inherent from both the natives and the colonialists. The women felt the unfairness of society's culture at that time. Therefore, there was a rebellion by women to destroy the perception that caused this injustice. So that appeared RA Kartini, the advocate of gender equality and as a pioneer of the emancipation of women in education in Indonesia in the XIX century.
\end{abstract}

Keywords: Works, Gender, Role Model, Struggle RA Kartini 


\section{PENDAHULUAN}

Kata "gender" secara bahasa dalam KBBI berarti "1 jodoh (laki-perempuan/jantanbetina)", namun kata ini tidak digunakan dalam KBBI yang memilki hak cipta dari Kemendikbud dan bahkan jarang sekali ditemukan dalam beberapa kamus bahasa Indonesia, kata ini hanya ada apabila dicari dalam tesaurus bahasa karya Eko Endarmoko. Secara istilah menurut beberapa ahli kata gender lebih identik dan sering dikaitkan serta melekat dalam kehidupan sehari-hari dengan 2 kata yaitu "kesetaraan gender". Kesetaraan yang dimaksud adalah adanya persamaan atas hak terkhusus perempuan terhadap lawan jenisnya yaitu lakilaki. Persamaan yang dimaksud mencakup segala bidang kehidupan dalam bermasyarakat (Nugroho, 2008: 15).

Munculnya wacana gender pada tahun 1977 didasari oleh karena adanya kesadaran pergaulan atas hak-hak perempuan yang menyebabkan arus informasi menjadi kritis dengan apa yang dialami oleh kaum perempuan. Hak-hak yang diperjuangkan oleh kaum perempuan di Indonesia itu merupakan andil dari kaum perempuan yang ada di seluruh dunia. Hal tersebut sudah barang tentu disebabkan oleh kelompok kaum perempuan ferminis di London yang lebih memilih menggunakan isu-isu gender discourse dibandingkan isu patriarcal. Masalah gender di Indonesia lebih dikenal dengan istilah "emansipasi wanita" dengan icon RA Kartini. Beliau sebagai perintis yang membawa kaum perempuan kearah jalan terang menuju perhatian bangsa dan cita cita nasional yang luhur. Meskipun belum sampai pada tahap yang diharapkan dan kesadaran RA Kartini untuk mencapai cita-citanya masih banyak halangan dan rintangan namun keoptimisan dem menggapai yang diharapkannya akan dapat diteruskan pada generasi selanjutnya (Hardi, 1985: 18).

Menurut hemat penulis apa yang ada dalam pikiran RA Kartini adalah hanya dengan diberikan pendidikan maka kedudukan kaum perempuan dapat setara dengan kaum laki-laki ditengah-teangah masyarakat. Apa yang ada didalam pikiran RA Kartini dituangkan dalam bentuk tulisan kemudian menjadi sebuah buku dengan judul "Habis Gelap Terbitlah Terang". Dalam pandangan penulis, dari karya RA Kartini yang diterjemahkan oleh Armjin Pane, bahwasanya karya tersebut membuka pandangan yang cerah akan harapan serta wawasan bagi kaum perempuan di Indonesia kala itu. RA Kartini banyak mengugkapkan cita-cita perjuangan yang besar akan kesadaran bangsa agar lebih peduli dengan keadaan kaum perempuan namun, sayang sekali cita-cita Kartin tersebut malah dianggap sepele oleh pemerintah dan masyarakat (Sudiyo, $2004: 21$ ). 
Munculnya ide/doktrin tersebut menurut penulis telah membawa perubahan besar didalam tubuh para kaum perempuan sehingga kaum perempuan akan mampu mengangkat martabat serta memajukan pendidikan dikalangannya. RA Kartini telah melahirkan semangat juang untuk kaum perempuan Indonesia demi melawan dan menentang adat istiadat yang sudah dilakukan secara turun temurun serta menjadi pengikat ketertinggalan kaum perempuan di Indonesia. Kemudian dengan munculnya ide tersebut akan mampu meningkatkan mutu pendidikan sehingga menumbuhkan kesadaran bagi kaum perempuan. Peningkatan tersebut ditandai dengan munculnya pergerakan-pergerakan kaum perempuan di berbagai daerah di Indonesia. Dari penjelasan diatas, maka menurut penulis terdapat banyak pelajaran dari sisi edukatif yang dapat dibuktikan dan dilihat dari para penggaung dan pemerhati nasib kaum perempuan pada abad XIX di Indonesia.

\section{METODE}

Metode penelitian adalah suatu kegiatan yang dilakukan secara ilmiah untuk mendapatkan data dengan prosedur tertentu yang digunakan dalam sebuah penelitian tertentu pula. Dalam melakukan penelitian ini penulis menggunakan metode penelitian sejarah dengan pendekatan studi pustaka. Guna mengungkapkan penelitian ini, maka penulis melaksanakannya sesuai dengan prosedur sebagai berikut.

1. Heuristik (Pengumpulan Sumber)

Heuristik adalah suatu posedur dalam penelitian sejarah yang pertama. Heuristik bertujuan untuk mengumpulkan semua sumber yang dianggap perlu. Data yang diperoleh berasal dari kumpulan buku, jurnal maupun catatan-catatan yang berkenaan dengan topic penelitian.

2. Verifikasi

Verifikasi atau kritik sumber merupakan kegiatan mengungkapkan keaslian dari pengumpulan sumber setelah heuristik pada tahap awal sebuah penelitian sejarah. Keaslian itu sifatnya berupa kritik interen dan eksteren sebuah sumber sejarah (Abdurrahman, 2007: $31)$.

\section{Interpretasi}

Interpretasi merupakan tahap penelitian sejarah yang ketiga setelah heuristik dan verifikasi. Apabila telah dilakukannya pengumpulan sumber dan melakukan kritik dalam mengungkapkan keabsahan dan keaslian sumber dari topic yang akan diteliti maka langkah selanjutnya adalah menganalisa sumber-sumber tersebut dengan melakukan penafsiran data 
serta fakta sesuai kaidah-kaidah dalam pengungkapan penelitian sejarah (Abdurrahman, 2007: 33).

\section{Historiografi}

Historiografi menurut Dudung Abdurrahman adalah langkah terakhir dalam metode penelitian sejarah. Setelah ketiga metode penelitian telah terlengkapi dengan syaratsyaratnya telah terpenuhi, maka tugas peneliti yang terakhir adalah menulis serta membuat laporan hasil dari penelitian yang telah dilakukan.

\section{HASIL DAN PEMBAHASAN}

\section{Munculnya Pergerakan Kaum Perempuan Pada Abad XIX}

Latar belakang dari bermunculannya pergerakan kaum perempuan pada abad XIX di berbagai daerah di Indonesia tentunya tidak terlepas dari pergerakan kaum perempuan yang dipelopori oleh RA Kartini di pulau Jawa dan dukungan dari kaum perempuan di seluruh belahan dunia. Terkhusus di Indonesia gerakan tersebut berasal dari aneka ragam ideologi yang berkembang pada masa penjajahan Belanda sehingga akibatnyapun terbentuklah berbagai organisasi perjuangan. Bagi kebanyakan rakyat Indonesia pada masa penjajahan untuk meraih akses pendidikan secara baik amatlah sulit dan pendidikan tersebut hanya dapat dirasakan oleh kaum priyai dan bangsawan (Abdullah, 2006: 37).

Pada masa kolonial Belanda struktur adat dan tradisi di Indonesia cukup kuat mengikat kehidupan pribumi di segala bidang kehidupan. Berbeda dengan kaum laki-laki yang dapat mengenyam pendidikan walaupun terbatas, kaum perempuan malah bisa dikatakan seluruhnya belum dapat menikmati pendidikan. Karena kenyataan itulah yang membuat masyarakat secara turun temurun menempatkan derajat perempuan hanya sebagai pendamping suami dalam mengurusi kebutuhan rumah tangga .Tokoh-tokoh perempuan di Indonesia mulai bermunculan atas dasar keprihatinan tersebut (Kowani, 1978: 56).

Para putra-putri pribumi yang bersekolah di Eropa pada abad XIX semakin menaruh minat besar, wajar saja apabila para kaum perempuan yang telah bersekolah menjadi pelopor munculnya prakarsa membangun sekolah bagi kaum perempuan di Indonesia. Selain mengasah keterampilan dan kecerdasan kaum perempuan juga dapat membangun norma sopan dan santun serta kesusilaan. Pelopor kesetaraan dan kebebasan yang dikenal dengan emansipasi wanita oleh anak dari bupati Jepara yaitu RA Kartini. Cita-cita beliau adalah menyetarakan pendidikan bagi kaum perempuan agar sejenjang dengan kaum laki-laki. Hal ini tertuang dalam tulisan 
beliau berbentuk surat yang ditujukan kepada sahabat-sahabatnya di Belanda. Pada tahun 1911diterbitkanlah buku yang berjudul "Habis Gelap Terbitlah Terang”. Buku ini berasal dari kumpulan surat RA Kartini dalam menuangkan harapan dan cita-cita beliau untuk kemajuan kaum perempuan di Indonesia. Di dalam tulisan RA Kartini tersebut digambarkan pola pikir orang tua terhadap anak-anaknya, taat serta patuhnya terhadap adat istiadat yang berlaku kala itu, termasuk pula kaidah tata susila, tata krama, dan cara mengaur hubungan sosial kemasyarakatan (Sulastin, 1979: 45).

\section{Kemunculan Doktrin Gender di Indonesia Abad XIX}

Sebuah pergerakan akan timbul apabila adanya semangat yang terpacu dengan kuat kearah perbaikan dikarenakan tertanamnya sebuah ketimpangan. Hal ini pulalah yang penulis analogikan dengan gerakan kaum perempuan di Indonesia. Secara sejarah gerakan kaum perempuan di berbagai negara umumnya disebabkan oleh kondisi pemerintahan setempat ditinjau dari segi sosial politik. Gerakan kaum perempuan di Indonesia berupaya untuk menuntut pemerintah agar menyamaratakan kultur ditengah-tengah masyarakat. Kemudian gerakan kaum perempuan lebih focus dalam kesetaraan pendidikan agar status sosialnya dapat setara dengan laki-laki pada masa itu (Pane, 2006: 49).

Perempuan dikekang oleh kebudayaan yang sudah mengikat disertai dengan tatanan adat istiadat turun temurun bahwasanya perempuan jauh lebih rendah dibanding laki-laki. Tugas perempuan hanyalah mengurus urusan rumah tangga dan segala pekerjaan rumah tangga. Perempuan hanya sebatas the second sex begitu rendahnya derajat peremuan masa itu sehingga ada juga ungkapan suwargo nurut neroko katut yang berarti kebahagiaan dan penderitaan istri tergantung suami. Ungkapan-ungkapan tersebut sangat berlaku pada abad XIX dimana perempuan dianggap tidak berperan dalam kehidupan. Ungkapan ini sangat dominan hingga pergantian abad XX (Soeroto, 1977: 78).

Berdasarkan pemaparan diatas bagi pemahaman penulis, secara historis menunjukkan bahwa kenyataan itu harus berakhir seiring datangnya kultur modernisasi. Dengan contoh para pemuda Jawa terpelajar mendirikan organisasi Boedi Oetomo karena tidak tahan dengan kondisi kala itu sehingga terjadilah pemberontakan yang sangat penting bagi perjalanan nasionalisme Indonesia. RA Kartini telah berjuang dalam upaya mengangkat kaum perempuan dalam berbagai bidang tidak hanya dibidang pendidikan namun efek dari pendidikan itu dapat pula dirasakan dalam segala bidang kehidupan masyarakat seperti sosial, budaya, ekonomi, adat istiadat, dan modernisasi serta nasionalisme. 


\section{Perjuangan Serta Cita-Cita RA Kartini}

RA Kartini memperjuangkan pendidikan bagi kaum perempuan didasari oleh keadaan Indonesia saat itu. Keadaan kaum perempuan di Indonesia masih sangat terbelakang dan jauh tertinggal. Kaum perempuan diikat oleh budaya dan tatanan adat istiadat nenek moyang secara turun temurun. Mereka hanya dianggap sebagai manusia yang patuh akan kewajiban dan kodratnya sebagai perempuan. Apa yang mereka lakukan hanya sebatas mengurus anak serta kebutuhan rumah tangganya dan melayani suami tanpa harus mengetahui apa yang terjadi didunia luar. Kaum perempuan harus patuh terhadap ayah, ibu, saudara serta suami. Kepatuhan itu sudah ditanamkan sejak kecil, maka tak jarang kaum perempuan pada masa itu banyak yang belum cukup umur dalam berumah tangga. Akibatnya laki-laki menjadi tinggi hati dan hanya memikirkan diri sendiri. Kaum perempuan tidak memilki kebebasan dalam bekerja terlebih lagi memiliki jabatan dalam masyarakat. Menurut Tashadi, kaum peremuan Indonesia abad XIX sangat mentaati adat sopan santun, adat perkawinan, dan semua adat istiadat yang berlaku mereka taati dan laksakan dengan tertib (Tashadi, 1986: 100).

Keadaan seperti yang sudah dipaparkan diatas juga dialami oleh RA Kartini, sebagai seorang yang dilahirkan dari kalangan priyai, beliau turut merasakan apa yang dialami para kaum perempuan itu sangatlah berat. Ditambah lagi orang tuanya berasal dari keluarga bangsawan yang tentu akan memegang teguh prinsip adat istiadat tersebut. Karena berasal dari keluarga bangsawan itulah beliau dapat mengenyam pendidikan dan berpikiran lebih maju dari kaum perempuan lainnya. Kemajuan yang dapat dirasakan oleh RA Kartini ditunjukkan dengan keinginannya untuk bebas dari belenggu adat istiadat nenek moyang yang mengikat, sudah tampak jiwa untuk berdiri sendiri dan terlebih setelah beliau turun langsung melihat keadaan kaum perempuan di Indonesia membuatnya sadar betapa bangsanya masih jauh terbelakang dan tertinggal (Honggowongso, 1990: 79).

RA Kartini dalam usia yang dikategorikan masih remaja, beliau telah memikirkan nasib kaumnya. RA Kartini berusaha untuk membebaskan kaumya dari belenggu ikatan adat istiadat dan juga mendesak kepada pemerintah kala itu agar merevisi kembali aturan politik yang terlalu merendahkan kaum perempuan. Dengan kondisi yang demikian, RA Kartini lebih memikirkan permasalahan yang menjadi pusat perhatian. Terkhusus pada pendidikan kaum perempuan kala itu. Apa yang dirasakan oleh masyarakat begitu pula dengan yang dirasakan oleh RA Kartini. Dan dari pada itu apa yang dicita-citakan oleh RA Kartini sebernarnya juga 
merupakan cita-cita seluruh masyarakat yang tak mampu diwujudkan karena belenggu ikatan adat istiadat yang sudah turun temurun (Komandoko, 2006: 91).

\section{Keteladanan Dari Seorang RA Kartini}

Setelah dipaparkan beberapa materi diatas, di sub judul ini penulis akan memaparkan beberapa keteladanan yang dapat kita contoh dari perjuangan serta cita cita beliau (RA Kartini) yaitu sebagai berikut.

1. Kesederhanaan RA Kartini.

RA Kartini merupakan anak dari bupati Jepara, ayahnya bernama Raden Mas Adipati Sosroningrat. Sedari kecil Beliau tidak memandang siapapun dalam berteman sehingga beliau dikenal sebagai sosok perempuan yang merakyat. Menurut beliau dalam isi suratnya berpendapat bahwa hanya ada 2 jenis bangsawan yaitu bangsawan budi dan bangsawan pikiran. RA Kartini menolak keras perilaku para bangsawan yang menindas rakyat dengan menggunakan alat kebangswanannya serta status sosial. RA Kartini lebih menghargai orang-orang berbudi dan berjiwa mulia (Toer, 2003: 107).

2. Berani

Sikap berani beliau ditonjolkan melalui perbedaan pandangan. Karena dianggap berbeda pandangan terhadap kaum perempuan RA Kartini pernah ditentang oleh kalangan masyarakat. Yang mana RA Kartini menganggap perempuan harus belajar dan memperjuangkan cita-citanya. Perempuan juga harus melihat keluar akan kemajuan zaman bukan hanya berada di dalam rumah dan menutup diri (Fakih, 1996: 97).

3. Mandiri

Kamandirian adalah salah satu sifat RA Kartini yang patut di contoh, cara beliau encari celah agar bisa berpengaruh bagi sekitar. Walaupun kartini tidak pernah memasuki ranah perguruan tinggi, namun beliau tetap belajar secara otodidak. Beliau Banyak belajar dari para sahabatnya dengan menulis surat-surat berisi kecaman oleh pemerintah pada masa itu. Dan hasilnya adalah beliau bisa membangun lembaga pendidikan bagi kaum perempuan dan menjadi sekolah pertama di pulau Jawa yang diperuntukkan bagi kaum perempuan.

4. Berwawasan

RA Kartini yang ssering mengirim surat untuk para sahabatnya di Belanda, membuat beliau berfikiran luas dan menjadi terbuka, hal itu ditandai dengan beliau menuntut hak-hak kaum perempuan agar disamaratakan dalam hal pendidikan dan juga dibidang yang lain seperti bekerja dan berpendapat. 


\section{Perempuan Yang Inspiratif}

RA Kartini dengan padangannya dan segala apa yang beliau lakukan dahulu tidak ada orang yang menyangka pandangan tersebut bisa menginspirasi banyak orang saat ini. RA Kartini menularkan pandangan-pandangan baru sehingga mampu membuat orang melakukan sesuatu kearah yang lebih baik. Segala hal yang berbau positif dilakukannya sangat berdampat baik bagi bangsa Indonesia saat ini.

\section{SIMPULAN}

Adapun kesimpulan yang dapat ditarik dari analisis yang telah dilakukan oleh penulis mengenai kesetaraan gender dalam karya RA Kartini, bahwasanya kesetaraan yang dimaksud adalah dengan memperoleh pendidikan yang baik bagi kaum perempuan dan bukan sematamata menyaingi laki-laki namun hanya ingin memperoleh pendidikan yang layak dan sama dengan laki-laki. Fenomena kesetaraan gender nampaknya tak akan pernah habis untuk dibahas, kaum perempuan merupakan sumber inspirasi dalam segala dinamika kehidupan. Kajian mengenai perempuan sudah merupakan hal yang lazim dibandingkan laki-laki. Harus diakui bahwa status perempuan dalam kebudayaan kita tak seberuntung status laki-laki.

Pada masa abad ke XIX, para perempuan di berbagai dunia termasuk wilayah Asia sendiri mulai menuntut keadilan agar disamaratakan martabat serta haknya dengan kaum lakilaki. Sehingga tak mampu dipungkiri bahwa munculnya pergerakan perempuan menuntut kesetaraan gender di Indonesia adalah imbas dari peregerakan perempuan di seluruh dunia. RA Kartini adalah icon pertama yang menyerukan persoalan tersebut. Secara historic kaum perempuan adalah pondasi dari kemajuan suatu bangsa serta perannya dalam turut andil pembangunan bangsa tersebut. Seperti ucapan presiden Soeharto tanpa mengikutcampur tangankan perempuan pembangunan bangsa tidak berarti apa (pincang). Pendidikan merupakan pondasi dasar yang kuat bagi kaum perempuan dan dikontruksikan secara sosial menujju kesejahteraan dan kesetaraan, yang mana hal tersebut akan selalu berubah dari waktu ke waktu menurut budaya modern tertentu.

\section{DAFTAR PUSTAKA}

Abdullah, I. (2006). “Sangkan Paran Gender”. Yogyakarta: Pelajar Offset Abdurrahman, D. (2007). “Metodologi Penelitian Sejarah”. Jakarta: Ar Ruzmedia. 
Fakih, M. (1996). “Analisis Gender dan Transformasi Sosial”. Yogyakarta: Pustaka Pelajar.

Hardi, L. (1985). “Sumbangsihku Bagi Pertiwi”. Jakarta: PT. Dunia Pustaka Jaya.

Honggowongso, S. H. 1990. Perjuangan Wanita Sejagat Menuntut Hak Politik. Jakarta: Balai Pustaka.

Komandoko, G. (2006). “Kisah 124 Pahlawan dan Pejuang Nusantara”. Jakarta: Pustaka Widyatama.

Kowani. (1978). “Sejarah Setengah Abad Pergerakan Wanita Indonesia”. Jakarta: Balai Pustaka.

Nugroho, R. (2008). "Gender dan Strategi Pengurus Utamanya di Indonesia". Yogyakarta: Pustaka Pelajar.

Pane, A. (2006). Habis Gelap Terbitlah Terang. Jakarta: Balai Pustaka.

Soedjatmoko dkk. 1995. Historiografi Indonesia. Jakarta: Pustaka Utama.

Soeroto, S. S. 1977. Kartini Sebuah Biografi. Jakarta: Gunung Agung.

Sudiyo. Drs. 2004. Pergerakan Nasional Mencapai dan Mempertahankan Kemerdekaan. Jakarta: Rineka Cipta.

Sulastin, S. 1979. Surat-Surat Kartini Renungan untuk Bangsanya. Jakarta: $\quad$ Pustaka DJambatan.

Tashadi. 1986. RA Kartini. Jakarta: Depdikbud.

Toer, A. P. 2003. Panggil Aku KartiniSaja. Jakarta: Lentera Dipantara. 